\title{
Step-by-step surface roughness formation during shot peening and subsequent grinding with flap wheels
}

\author{
Koltsov Vladimir \\ Doctor of Engineering Sciences, Professor of the \\ Department of «Technology and Equipment of Machine- \\ Building Productions» \\ Federal State Budget Educational Institution of Higher \\ Education «Irkutsk National Research Technical \\ University» \\ Irkutsk, Russia \\ e-mail: kolcov@istu.edu.ru

\section{Starodubtseva Daria \\ Graduate student} \\ Federal State Budget Educational Institution of Higher \\ Education «Irkutsk National Research Technical \\ University» \\ Irkutsk, Russia \\ e-mail: d.star-irk@yandex.ru
}

\author{
Le Tri Vinh \\ Candidate of Engineering Sciences, Associate Professor of \\ the Department of «Technology and Equipment of Machine- \\ Building Production» \\ Federal State Budget Educational Institution of Higher \\ Education «Irkutsk National Research Technical \\ University» \\ Irkutsk, Russia \\ e-mail: vinh_istu@mail.ru
}

\section{Phung Xuan Son}

Candidate of Engineering Sciences, Deputy Dean of the Faculty of mechanical engineering, head of the Department of industrial equipment and tools Hanoi University of Industry Hanoi, Vietnam

e-mail: phungxuanson@gmail.com.com

\section{INTRODUCTION}

In aircraft building, for generation of complex curvilinear surfaces of panels and sheaths and also for hardening, shot peening (SP) is widely used. Grinding with flap wheels is a mandatory technological operation during forming the longsized and large-sized surfaces of panels and sheaths, this operation is carried out in order to improve the quality of the initial surface obtained after shot peen forming [1-5].

When a shot flow acts on the surface machined, a specific surface roughness profile is formed on the part surface. It has numerous shot peening dimples of different diameters and depths [6-9]. At this time, a distribution of dimples on the surface machined is chaotic (random) and the depth values of most shot peening dimples are larger than the roughness depths values resulted from previous machining processes.

The operation, preceding shot peening treatment, as a rule, is machining (usually milling) with its own characteristics and parameters of surface roughness. As a result, on the surface microrelief formed by a previous operation, the traces of shot peen impact are applied, and a new profile of micro-roughness is formed on this surface.

The dimples as the traces of shot on the new microrelief have different diameters and depths, which significantly exceed the level of micro-roughness from previous machining. At the same time, a distribution of these dimples on the treated surface is chaotic (random) [10]. An actual combination of microreliefs of these operations allows one to form a new microrelief of the part surface. Thus, a systematic mechanical 
machining profile (process) is superimposed by a random process which is a set of chaotically arranged shot peening dimples with different depth values. Practical integration of these processes forms a new surface microrelief with properties of a random process.

The presence of the set of dimples, the value of which exceeds the initial level of surface microroughness, increases the values of surface roughness parameters of the part, which causes displacement of the original center plane of surface roughness profile.

When measuring roughness parameters for a threedimensional surface topography with properties of a random process, a basic surface area ensuring accurate results should be determined. The value of the basic surface area should depend on the density of random surges. In shot peening, a coverage degree (a relation of the total shot peening dimples area in the sector under study to the whole sector area) can be used as the parameter which indicates the density of surges.

Previous researches of the authors [7] identified dependencies of the basic sector area on the degree of coverage. It is evident that the base surface area for the available coverage degree is crucial for determining the surface roughness after shot peening.

\section{DETERMINING ROUGHNESS PARAMETERS FOR THE BASE AREA AFTER SHOT PEENING}

The theoretical degree of coverage can range from 0 to 100 $\%$. For shot peen forming, the degree of coverage falls within the range of $30-40 \%$, and for shot hardening - of $100 \%$ [11, 12]. There is no doubt that at any degree of coverage a surface roughness formation after SP is a random process. The number and depth of shot peening dimples in the controlled surface sector influences roughness parameters. Roughness parameters, measured along the area which is smaller than the basic one, are different. When the area of the controlled sector approximates to the base one, roughness parameters are stable, and when the controlled area increases, they are more constant.

Figure 1 shows the scheme of the conditioned profile of the shot peening dimple with the original surface (after applying profiles milled and machined by shot peening).

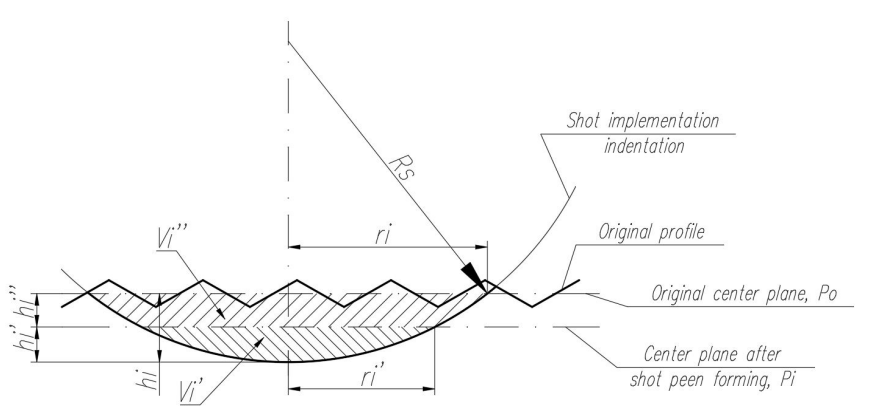

Fig. 1. The scheme of profile after shot indentation on milled surface

Figure 1 includes the following designations: $R_{s}$ - radius of shot; $h_{i}$ - shot indentation depth from center plane $P_{0} ; h_{i}{ }^{\prime}{ }^{\prime}-$ distance from original center plane $P_{0}$ to center plane after shot peening $P_{i} ; h_{i}{ }^{\prime}-$ shot indentation depth to center plane $P_{i}$; $r_{i}$ - radius of shot peening dimple in original center plane $P_{0}$; $r_{i}$ ' - dimple radius in center plane $P_{i} ; V_{i}$," - volume of dimple between center planes $P_{0}$ and $P_{i} ; V_{i}^{\prime}$ - volume of dimple below center plane $P_{i}$.

The base surface is used to assess roughness parameters. It is a part of the nominal part surface which is a part surface set without regard to admissible roughness values.

In order to determine roughness parameters within the base area, it is necessary to find a center plane of surface profile $P_{i}$ after shot peening. According to the methods used for determining a center plane of three-dimensional surface topography and roughness parameters within the base area $[10,13]$ (where the base area is square with side equal to base length), a center plane is a plane with equal volume of material above and volume of voids below within the base area. As far as shot peening causes dimples along the part surface most whose depths exceed the original roughness depth value, it can be assumed that the center plane after SP is below the original center plane of the milled surface.

If $P_{0}$ is the center plane of the original milled surface before SP, and the roughness of milled surface is rather uniform regarding to center plane, an entire body is formed under $P_{0}$, as the total volume of material above $P_{0}$ compensates for the total volume of voids below $P_{0}$.

If $F_{b}$ is the base area, the total volume of material to center plane $P_{i}$ is determined as (1):

$\sum$ volume of voids below $P_{i}=\sum$ volume of material above $P_{i}$

i.e.

$$
\sum_{i=1}^{n} V_{i}^{\prime}=F_{b} \cdot h_{i}^{\prime \prime}-\sum_{i=1}^{n} V_{i}^{\prime \prime}
$$

Here

$$
\sum_{i=1}^{n} V_{i}^{\prime \prime}=\sum_{i=1}^{n} V_{i}-\sum_{i=1}^{n} V_{i}^{\prime},
$$

where $V_{i}$ - total volume of the valley of $i$-th dimple.

Then:

$$
\sum_{i=1}^{n} V_{i}^{\prime}=F_{b} \cdot h_{i}^{\prime \prime}-\left(\sum_{i=1}^{n} V_{i}-\sum_{i=1}^{n} V_{i}^{\prime}\right)
$$

or

$$
\sum_{i=1}^{n} V_{i}=F_{b} \cdot h_{i}^{\prime \prime}
$$

Distance $h i$ ' 'from original center plane $P_{0}$ to center plane after SP Pi is determined as (6): 


$$
h_{i}^{\prime \prime}=\frac{\sum_{i=1}^{n} V_{i}}{F_{b}} .
$$

As far as the valley form is nearly spherical [7], the volume of each $i$-th dimple is the volume of sphere segment with the height $h_{i}$, (7):

$$
h_{i}^{\prime \prime}=\frac{1}{F_{b}} \cdot \sum_{i=1}^{n} \pi \cdot h_{i}^{2} \cdot\left(R_{S}-\frac{1}{3} h_{i}\right) .
$$

It is known that [10] the arithmetic mean deviation of the profile within the base area can be determined by formula (8):

$$
S a=\frac{1}{F_{b}} \iint|\eta(x, y)| d x d y,
$$

where $S a$ - arithmetic mean deviation of the profile within the base area; $F_{b}$ - base area; $x, y$ - coordinates; $\eta(x, y)$ - function

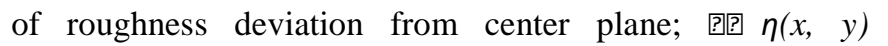
describes a total volume of material above center plane and a total volume of voids below center plane.

As the roughness of the part surface after SP is undefined, it is difficult to find a uniform function of roughness deviation from center plane. The center plane should be divided into $m$ sectors, in which the surface profile deviation follows some continuous function $F\left(u_{j}\right)$. Then the volume of material of $j$-th sector is determined as (9), [10]:

$$
V\left(u_{j}\right)=\int_{0}^{u} F\left(u_{j}\right) d u_{j}
$$

where $V\left(u_{j}\right)$ - volume of area restricted to field $H(x, y)$ (surface) and plane which is parallel to coordinate plane $(x, y)$ at distance $u$.

If the above center plane is plane $(x, y)$, and $u$ ranges from 0 to $u_{\max }$ (maximum value of each profile peak or valley), the total volume of material or voids above or below center plane $P_{i}$ is determined as (10):

$$
\sum_{j=1}^{m} V\left(u_{j}\right)=\sum_{j=1}^{m} \int_{0}^{u} F\left(u_{j}\right) d u_{j}
$$

As far as the total volume of material above the center plane is equal to the total volume of voids below it, the arithmetic mean deviation of the profile from the center plane within the base area can be written as (11):

$$
S a=\frac{1}{F_{b}} \cdot \sum_{j=1}^{m} \int_{0}^{u} F\left(u_{j}\right) d u_{j}=\frac{2}{F_{b}} \cdot \sum_{i=1}^{n} V_{i}^{\prime} .
$$

Based on formula (3) and a close-to-spherical dimple of shot peening, we have (12):

$$
\begin{gathered}
S a=\frac{2}{F_{b}} \cdot \sum_{i=1}^{n} \pi \cdot\left(h_{i}^{\prime}\right)^{2} \cdot\left(R_{S}-\frac{1}{3} h_{i}^{\prime}\right)= \\
=\frac{2 \pi}{F_{b}} \cdot \sum_{i=1}^{n}\left(h_{i}-h_{i}^{\prime \prime}\right)^{2} \cdot\left(R_{S}-\frac{1}{3}\left(h_{i}-h_{i}^{\prime \prime}\right)\right) .
\end{gathered}
$$

The formula (12) determines $S a$ after SP without regard to original surface roughness. Based on the original surface roughness, the total arithmetic mean deviation of the profile $S a_{t}$ can be determined by formula (13):

$$
S a_{t}=0.5 S a_{m}+\frac{2 \pi}{F_{b}} \cdot \sum_{i=1}^{n}\left(h_{i}-h_{i}^{\prime \prime}\right)^{2} \cdot\left(R_{S}-\frac{1}{3}\left(h_{i}-h_{i}^{\prime \prime}\right)\right)
$$

where $S a_{m}$ - arithmetic mean deviation of the profile within the base surface area after milling.

To check the validity of the proposed mathematical models (13) it was necessary to measure the depth of dimples on different parts of the surface scanning by optical method [13]. The results of measuring the depths of dimples at the stage of shot peening, as well as the depths of dimples after shot peen forming. Comparison of the results of calculations with the results produced by the optical profilometer confirmed the reliability of mathematical models.

III. DETERMINING ROUGHNESS PARAMETERS WITHIN THE BASE AREA DURING SHOT PEENING - GRINDING WITH FLAP WHEELS

The surface after shot-peen forming is subject to mandatory subsequent grinding in order to partially remove the traces because of impact of shots and to ensure the specified parameters of surface quality.

Regarding to the surface structure after shot-peen forming, the allowance value $a$, characterizing the value of removal of the dimples, is determined by the depth of the dimple (Fig. 2), [14].

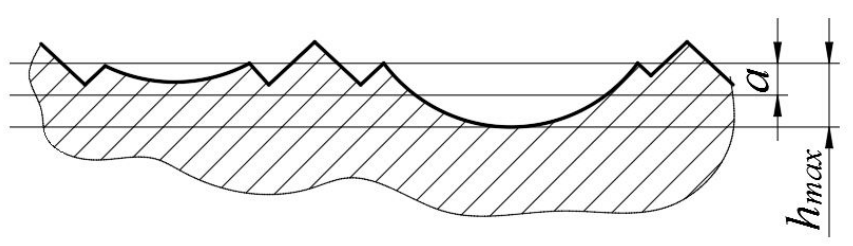

Fig.2. Schematic representation of the part surface treated by shot peening, where $\mathrm{h}_{\max }$-maximum depth of dimple; $\mathrm{a}$ - allowance, which will be removed during grinding 
The maximum value of dimple depth $h_{\max }$ in the investigated sector of the surface at stage of grinding must be reduced by the allowance amount $a$ for compliance with the requirements of design documentation and tolerance of the part. In this case, a removal of all traces of shot is not necessarily and in the result after grinding, a large number of shot dimples is remained.

Figure 3 shows the result of the optical profilometer scan (with Bruker Contour GT-K1 model) of the typical milled sample surface area, followed by shot peen forming with the shot radius of $1.75 \mathrm{~mm}$ at the shot-peen wheelspeed of 800 $\mathrm{rpm}$ and the longitudinal feed of $2 \mathrm{~m} / \mathrm{min}$. Figure 4 shows the surface profile through one of the largest shot peening dimple in the investigated area. While $(R a 3.981 \mu \mathrm{m}$, while $R p$, which characterizes the magnitude of the highest peak of profile $18.711 \mu \mathrm{m}$, deepest valley profile $R v 41.249 \mu \mathrm{m})$.
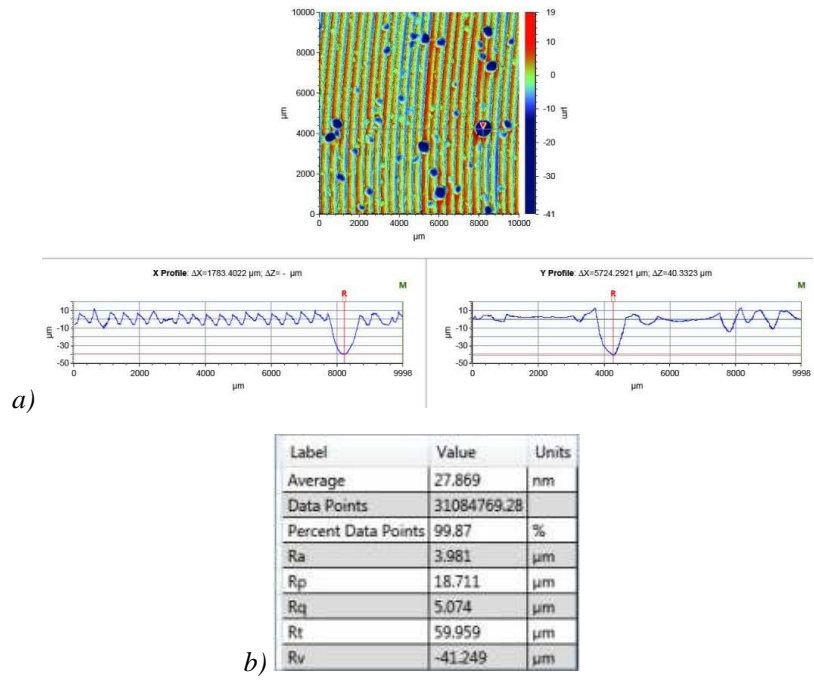

Fig. 3. Scan results of sample surface after shot peen forming, a) scanned surface profile of largest dimple after shot peening, b) measurement result

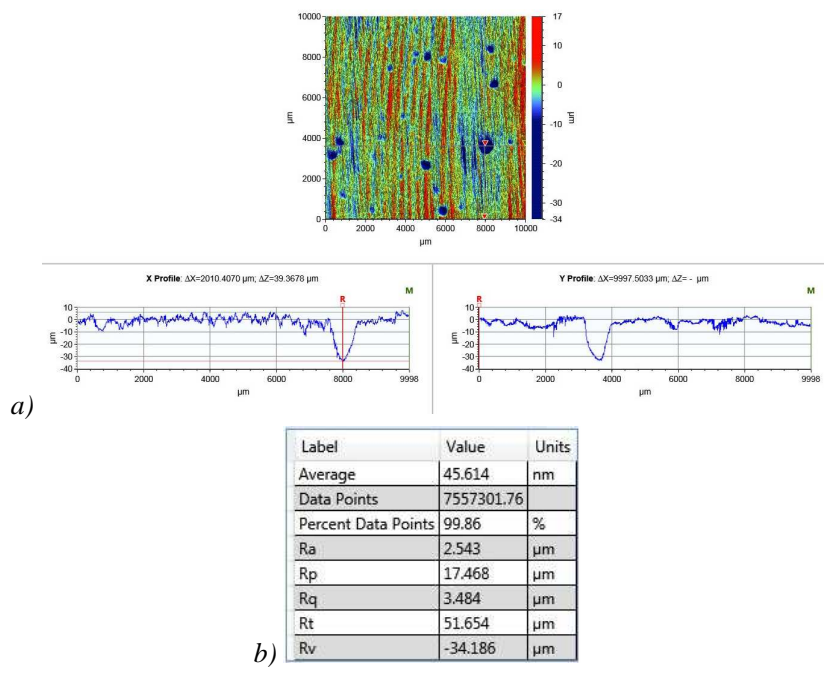

Fig. 4. Scan results of sample surface after shot peen forming and subsequent grinding with flap wheels, a) scanned surface profile of largest dimple after grinding with flap wheels, b) measurement result
Figure 4 shows the profile of the same scanned surface after shot peening in mutually perpendicular planes passing through the same shot dimple. Grinding is done with the $350 \times 100 \times 45 \mathrm{~mm}$ flap wheel made of abrasive flap KK751 P60 at the flap wheel speed of $1200 \mathrm{rpm}$, the longitudinal feed of $1.2 \mathrm{~m} / \mathrm{min}$ and the radial deformation of abrasive flap during contact with machining surface of $2.5 \mathrm{~mm}$ according to the technology used in practice.

After shot peening, the average value $R a$ within the investigated area amounted to $2.543 \mu \mathrm{m}, R p 17.468 \mu \mathrm{m}, R v$ decreased to $34.186 \mu \mathrm{m}$. It should be noted that the average value of the $R a$ parameter within the investigated area during grinding did not exceed the allowed value ( $R a$ 3.2) during processing of panels and sheaths.

In result of data review in figures 3 and 4 we can conclude that even in this slight removal of the allowance by flap wheels, on machining part the new surface micro-relief is formed, as combination of micro-roughness formed by successive stages of processing, including mechanical machining, shot peening and grinding. That is, after grinding, there are still many large dimples that are directly involved in forming the surface roughness of machining part.

Thus, the original center plane of surface profile formed by milling, is shifting down after shot peening [13]. In subsequent grinding the center plane also moves down when the material layer within the allowance is removed. That is, the center plane of profile after grinding is below the center plane of profile after shot peening.

Figure 5 presents the graphical diagram of location of main parameters of surface profile after milling, shot peening and grinding. At the same time, the basic parameters of surface roughness after grinding are determined on the basis of location of the center plane $P_{k}$.

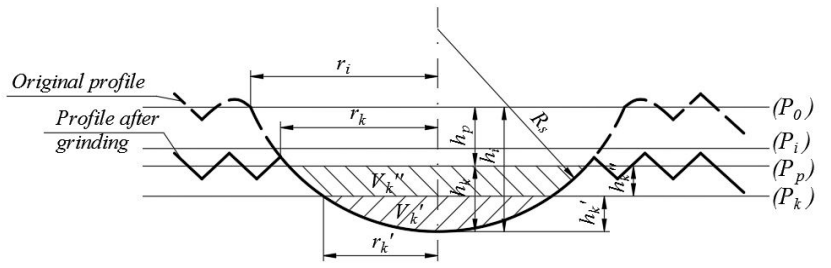

Fig 5. Diagram of main parameters of profile of machining part after milling, shot peening and grinding with flap wheels

Figure 5 includes the following designations: $h_{i}$ - depth of $k$-th dimple; $h_{p}$ - allowance value removed during grinding; $h_{k}$ -dimple depth after grinding; $h_{k}$ ' - dimple depth from center plane after grinding, including shot peen forming; $h_{k}$ " distance between center plane after grinding without taking into account shot peen forming $\left(P_{p}\right)$ and center plane after grinding $\left(P_{k}\right) ; r_{i}$-radius of dimple in center plane after milling $\left(P_{0}\right) ; r_{k}$-radius of dimple in terms of center plane $P_{P} ; r_{k}{ }^{\prime}-$ radius of dimple in terms of center plane $P_{k} ; V^{\prime}{ }_{k}$-volume of voids in dimple after grinding under center plane $P_{k} ; V_{k}{ }^{\prime \prime}$ volume of voids in dimple after grinding over center plane $P_{k}$.

If there are still a lot of dimples remained after grinding, then similarly to the method of determining the center plane after shot peen forming [13], the final position of center plane after grinding is determined by the following form (14): 


$$
h_{k}^{\prime \prime}=\frac{\sum_{k=1}^{t} V_{k}}{F_{b}}=\frac{1}{F_{b}} \cdot \sum_{k=1}^{t} \pi \cdot h_{k}^{2} \cdot\left(R_{S}-\frac{1}{3} h_{k}\right)
$$

where $t$ is the number of dimples remained after grinding with depths exceeded the level of original micro-relief; $V_{k}-$ the volume of voids of the $k$-th dimple under the center plane $P_{p}$;

Herewith,

$$
\begin{gathered}
\sum_{k=1}^{t} V_{k}=\sum_{k=1}^{t} V_{k}^{\prime}+\sum_{k=1}^{t} V_{k}^{\prime \prime} \\
h_{k}=h_{i}-h_{p}
\end{gathered}
$$

So

$$
h_{k}^{\prime \prime}=\frac{1}{F_{b}} \cdot \sum_{k=1}^{t} \pi \cdot\left(h_{i}-h_{p}\right)^{2} \cdot\left(R_{S}-\frac{1}{3}\left(h_{i}-h_{p}\right)\right)
$$

Similarly to the method proposed for determining roughness after shot peen forming, the arithmetic mean deviation of the profile within the base area after grinding is determined by the formula (18). The obtained dependence determines the value of $S a$ after shot peen forming without taking into account original surface roughness.

$$
\begin{aligned}
& S a=\frac{2}{F_{b}} \cdot \sum_{k=1}^{t} V_{k}^{\prime}=\frac{2}{F_{b}} \cdot \sum_{k=1}^{t} \pi \cdot\left(h_{k}^{\prime}\right)^{2} \cdot\left(R_{S}-\frac{1}{3} h_{k}^{\prime}\right)= \\
& =\frac{2 \pi}{F_{b}} \cdot \sum_{k=1}^{t}\left(h_{i}-h_{p}-h_{k}^{\prime \prime}\right)^{2} \cdot\left(R_{S}-\frac{1}{3}\left(h_{i}-h_{p}-h_{k}^{\prime \prime}\right)\right)
\end{aligned}
$$

The final formula for calculating the total arithmetic mean deviation of the profile within the base area after shot peen forming and grinding $S a_{t}$, taking into account the original roughness is determined as follows (19):

$S a_{t}=0.5 S a_{g r i}+\frac{2 \pi}{F_{b}} \cdot \sum_{k=1}^{t}\left(h_{i}-h_{p}-h_{k}^{\prime \prime}\right)^{2} \cdot\left(R_{S}-\frac{1}{3}\left(h_{i}-h_{p}-h_{k}^{\prime \prime}\right)\right)$,

where $S a_{g r i}$ is the arithmetic mean deviation of the profile within the base area after grinding, excluding shot peen forming.

Formula (19) is only valid with the condition of availability of sufficient number of the remained dimples. Otherwise, when the allowance value is close to the value of depth of the greatest dimples, the remained dimples of shot peening do not have a significant impact on roughness formation of treated surface after grinding. That is, the formation of surface roughness during grinding can be considered as a process of roughness formation during traditional processing with flap wheels.

However, when using shot peening with subsequent grinding with flap wheels, the parameters of surface roughness is largely determined by traces of shot peen impact.

\section{References}

[1] A.E. Pashkov, "Technological relationships under long sheet metal part manufacturing”, Irkutsk: IrGTU Publ., p. 138, 2005, (In Russian).

[2] A.E. Pashkov, "On the creation of a complex forming method for large panels", Highly efficient technologies of designing, design-engineering preparation and manufacturing of airplanes. All-Russian Scientifc and Practical Workshop with International Particiants. Scientific Production Corporation Irkut, Irkutsk National Research Technical University, 2011, pp. 103-110.

[3] A.E. Pashkov, "Automated combined forming of aircraft panels", Proceedings of Samara Scientific Center of the Russian Academy of Sciences, 2013, vol. 15 (6-2), pp. 453-457.

[4] A.Y. Malashchenko, "Research of technological capacities of the process of long-length skin forming by combination of roll-bending and peen forming processing”, Russian Aeronautics, 2016, vol. 59 № 2, pp. 254-258.

[5] A.E. Pashkov, A.A. Pashkov and V.P. Koltsov, "Complex method of peen forming and shot peening of aircraft structural components", Proceedings of the international conference "Actual issues of mechanical engineering", (AIME 2017), 2017, vol. 133, pp. 585-591.

[6] A.P. Chapyshev, "Statistical description of surface after shot peening", Proceedings of the regional scientific and technical conference «Promising technologies of materials manufacturing and machining», (Irkutsk, 25-26 September 2004), 2004, pp. 42-46, (In Russian).

[7] B.P. Koltsov, Vinh Le Tri and D.A. Starodubtseva, "To the problem of shot peening coverage degree determination", PROCEEDINGS of ISTU, 2017, vol 21, 11(130), pp. 45-52, (In Russian).

[8] A.E. Pashkov, A.P. Chapyshev, "Accounting of machining zone structure effect under shot peening forming", Interuniversity collection of scientific articles "Technological Mechanics of Materials", Irkutsk: IrGTU Publ., 2003, pp. 22-27, (In Russian)

[9] M.M. Matlin, V.V. Moseyko, "Probabilistic estimation of parameters of process of crushing and grinding", Izvestia of Volgograd State Technical University, 2005, vol. 2, pp. 35-38.

[10] A.P. Husu, Ju.R.Vitenberg and V.A. Pal'mov, "Surface roughness: theoretical and probabilistic approach", Moscow: Nauka Publ., p. 344, 1975, (In Russian).

[11] A.Ju. Dijak, "Promising methods to determine surface coverage under shot peening", Proceedings of Irkutsk State Technical University, 2014, vol. 7 (90), pp. 12-17.

[b] A.Ju. Dijak, "Shot coverage degree estimation by a computer-aided method", Proceedings of Irkutsk State Technical University, 2015, vol. 12 (107), pp. 19-25.

[13] V.P. Koltsov, Le Tri Vinh and D.A. Starodubtseva, "Surface roughness formation during shot peen forming", IOP Conference Series: Materials Science and Engineering,, 2018, vol. 327, 042125, doi:10.1088/1757899X/327/4/042125

[14] V.P. Koltsov, D.A. Starodubtseva and A.P. Chapyshev, "To a definition of an allowance value during grinding with flap wheels of panel and sheath surface after shot peen forming", Vestnik of Kazan State Technical University named after A.N. Tupolev, 2017, vol 73, 1, pp. 2530, (In Russian). 